\title{
Analysis of possibilities of high-speed prototyping technology in hot section manufacturing
}

\author{
Andrey V. Balaykin ${ }^{1}$, Roman A. Vdovin ${ }^{1}$, and Elena M. Dobryshkina ${ }^{1,{ }^{*}}$ \\ ${ }^{1}$ Samara University, Department of Engine Technology, 443086 Moskovskoye Shosse 34, Samara
}

\begin{abstract}
The article is devoted to the exercising of a trial technological process for the manufacture of gas turbine engine (GTE) hot sections by the example of a solid-cast nozzle block. To do this, the authors made up a plan of the experiment associated with the search for optimal conditions and parameters of a technological process of the sector master mold layerby-layer synthesis from a photopolymeric material. The paper tracks the interconnection between the parameters of a 3D printing system Objet Eden 350 and the materials in the growing process by the PolyJet technology and mechanical properties of a master mold in the context of their influence on the surface layer quality and geometric accuracy of the final GTE parts' casting. Based upon the analysis of the obtained research results and taking into account technical requirements, the authors managed to grow a nozzle block sector master mold, get wax models and conduct an experimental casting of a solid cast nozzle block wheel.
\end{abstract}

\section{Introduction}

In the process of new high-tech products development and manufacture special attention is paid to the speed of research\&development and testing\&engineering work stages which, in its turn, significantly depends on the production facility technology capabilities. The stage of part workpieces obtaining is one of the most expensive and labour-consuming, therefore, it is given a particular attention. Pilot production is characterized by multi-variant research, frequent structure change and refining and, consequently, a continuous correction of technology tooling to manufacture a pilot batch, high-speed prototyping technologies become relevant, especially, in case of cast part manufacture. High-speed prototyping has shown good results in pilot production as it is easily adapted to the manufacture of complex configuration parts, such as, for example, GTE blades [1].

The articles devoted to the research of PolyJet optimal modes find out that the key influence on the surface and mechanical quality characteristics is exerted by the position (orientation) of a synthesized model on the framework [2, 3, 4, 5, 6, 7, 8, 9].

The papers $[3,7,8,9]$ contain the results of the property analysis conducted for the samples manufacture with the help of the PolyJet technology after mechanical tests and roughness measurement. It was found that a glossy surface (parameter Full Glossy) allows

*Corresponding author: dobryshkina93@mail.ru 
one to obtain minimum roughness values $(\mathrm{Ra}=0.3 \div 0.9 \mathrm{um}, \mathrm{Rz}=0.9 \div 3.3 \mathrm{um}$ ), however, a glossy surface is not recommended at the growing of thin-walled parts. As for the model position on a framework, the model maximum dimensions shall be located in the plane XY to obtain the required roughness. In terms of mechanical characteristics (tensile strength) the authors drew a conclusion that the model maximum dimensions located along the $\mathrm{X}$ axis (along the printing block run) provides for the increased ultimate strength values.

It should be mentioned that the considered papers do not contain the research on the volume shrinkage evaluation and change of the geometric parameters of the samples grown by means of the PolyJet technology. The availability of such results would provide for a more correct $3 \mathrm{D}$ design of part casting and assigning of an aggregate casting shrinkage. Besides, all these research were conducted on the samples with a 4-mm thickness. The obtained results cannot be used for thin-walled samples with a 2-mm wall thickness and less as plastic deformation processes (stress-strain state) for thin-walled samples occur in a different way.

The advantage of papers [2,5] is that they provide the research of mechanical characteristics of photopolymeric materials FullCure applied in the PolyJet technology. The obtained results allow for the most appropriate selection of a necessary material depending on the conditions and loads acting on the model.

Therefore, the following research objectives were set:

1. To conduct a research on obtaining the structures with 2-mm walls with the help of the PolyJet high-speed prototyping technology.

2. To study the properties of a photopolymeric material and technological capabilities of the applied equipment.

3. To refine and exercise a trial technological process for the GTE hot section manufacture by the example of a solid cast nozzle block.

4. To study the parameters of the developed high-speed prototyping process.

5. To determine the high-speed prototyping efficiency and the nature of manufacturing errors.

\section{Equipment to conduct the experiment}

Within the framework of the research the authors used the following equipment: 3D printing system Objet Eden 350, coordinate measuring machine (CMM) DEA GLOBAL Performance, test machine Testometric FS 150 AX.

In addition, the authors used the following devices: profile recording instrument Hommel - Etamic Tester W55, portable percussion penetrometer Hardness Tester TH160, outside micrometer MC.

As a main (model) photopolymeric material a transparent material Transparent FullCure720 was used (capable of reproducing not only the external geometry but also an internal volume).

\section{Experimental approbation of high-speed prototyping method}

The research object are the hot section parts - GTE blades in the form of a solid cast nozzle block as the most critical and loaded parts in the engine. They are characterized by a complex spatial form, high requirements to the accuracy of geometrical parameters and a surface layer quality. Due to a complex spatial form and the absence of developed surfaces for an accurate blade locating in the most efficient way, and in some cases the only one to obtain solid cast nozzle block workpieces, is a casting method to manufacture the workpieces with a further mechanical treatment of a locking area and shroud platform 
without airfoil allowances. A small-dimensioned interblade space of a nozzle block causes significant difficulties at mechanical treatment. Due to this reason an airfoil section is made by means of casting without airfoil allowances. To determine a shrinkage factor for a casting and the correspondence to the roughness parameters set in the design documents, one needs to conduct equidistant rolling on a synthesized master mold along the airfoil. This allowance is taken out at the polishing of the grown 3D models thus providing for a required roughness and surface quality on the master mold, and these parameters are inherited by nozzle block wax models by means of replication through a silicone elastic mold.

Therefore, the purpose of this research is to determine the interconnections between various parameters of the unit Eden 350, the materials in the process of their growing by the PolyJet technology and the printed part mechanical properties and their influence on the surface quality and geometric accuracy of the final solid cast GTE nozzle block. The qualitative results of the research conducted on the witness samples will allow for the correction of a nozzle block geometry at the stage of a 3D model and use optimal technological modes in the process of its manufacturing.

\subsection{Research of samples made by the PolyJet technology}

The most critical stage in high-speed prototyping is manufacturing a physical prototype according to its 3D model. Basing upon this, the authors stated key requirements set forth for master molds and the PolyJet technology to obtain the part prototypes of a required quality. Within the conducted research a particular attention was paid to the grown part surface roughness, growing modes (mat or glossy), research of key mechanical characteristics at the strength tests and location of synthesized models on the unit framework. The research were conducted in compliance with a full factor experiment method. To do this, 36 samples [10] were grown with various growing direction, surface types and support material consumption rate (Table 1) on the basis of which the authors further determined the influence of the above-mentioned parameters.

It should be mentioned that, to minimize the influence of random parameters of the researched process on the final experiment outcome, one needs to conduct the series of experiments under the same conditions - to randomize the experiments in time. Therefore, the number of researched samples increased up to $72 \mathrm{pcs}$.

The study of grown samples' surface roughness was conducted to select the most optimal orientation and parameters of the growing process and obtaining of the items with a minimum roughness, and every sample was subject to the roughness measurement in longitudinal and transverse directions.

The analysis of sample surface roughness research results showed the minimum roughness Ra $0.01 \div 0.8$ um is characteristic for the samples under the numbers: $4,5,6,7,8$, $9,10,11,12,28,29,30$. It demonstrates that the models with a minimum size at growing should be located along the $\mathrm{X}$ axis while the models with a minimum size - along the $\mathrm{Y}$ axis (direction perpendicular to the growing plane). At this, a glossy coating is preferable (Full Glossy). The amount of support material in the growing process does not significantly influence the obtained surface roughness. The samples which were vertically grown up (19, $20,21,31,32,33)$ have the highest surface roughness Ra $11.38 \div 22.27 \mathrm{um}$. One should avoid such location of models on the framework during a layber-by-layer growing. 
Table 1. Options of researched sample combinations

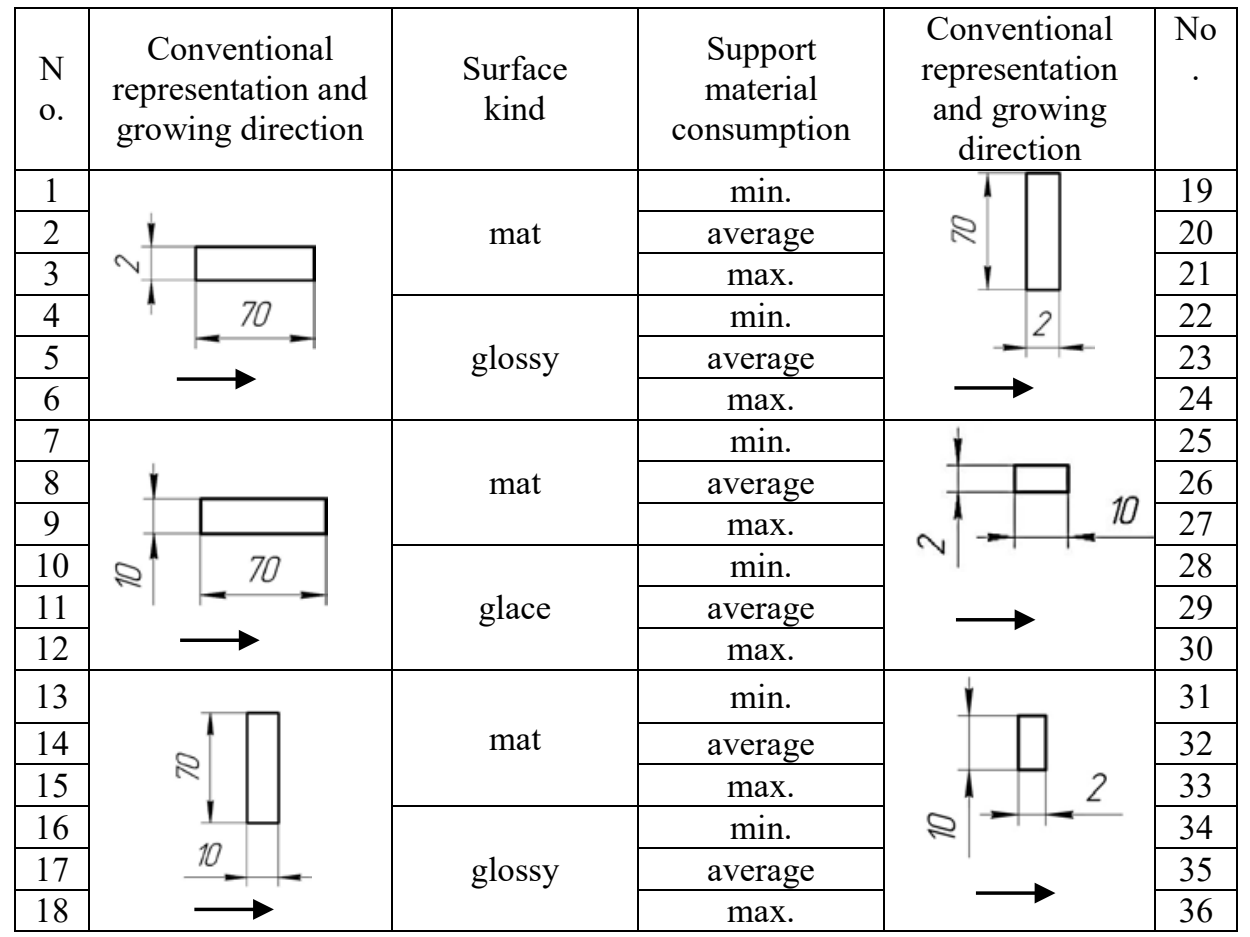

Note: $\min$ - minimum material consumption rate, average - average material consumption rate, max - maximum material consumption rate

Determining a free linear shrinkage and evaluating the stability of geometrical dimensions were conducted for the same samples at the ambient temperature. The material temperature at growing is $+75^{\circ} \mathrm{C}$. After growing the support material was eliminated with the help of the WaterJet unit. The sample storage temperature was equal to $+17 \ldots+19{ }^{\circ} \mathrm{C}$. The measurement of sample linear dimensions was conducted with the help of smooth micrometers $\mathrm{MC}$ with the measurement range 0-25, 25-50 и 50-75 with a division value $0.01 \mathrm{~mm}$ and permissible error $\pm 0.004 \mathrm{~mm}$. The samples were subject to the measurement of three linear dimensions corresponding to (LxDxW) 70x10x2 mm on a 3D model.

The analysis of the research on the linear shrinkage and model orientation influence onto a dimensional accuracy showed that the most stable geometric dimensions with minimum deviations from the nominal ones were obtained for the samples 5, 7, 8, 9, 15, 28 which is equal to $70^{+0,15} ; 10_{-0,05}^{+0,15} ; 2_{-0,05}$. These samples correspond to the options at which the maximum dimension of the model is located along the $\mathrm{X}$ axis in the $\mathrm{XY}$ plane. The mat surface is preferable. The obtained results shall be taken into account at the assigning of aggregate shrinkage for a part casting in the process of a master mold manufacture.

Mechanical properties are definitive for material structural strength. In the form of numbers they characterize material behavior under the influence of external loads which allows for their comparison and rational selection for various product manufacture. The hardness tests are one of the most wide-spread types of mechanical tests. The grown sample hardness was measured by means of the Leeb principle (HL). This method is a direct standardized (ASTM A956) hardness measurement.

The analysis of hardness measurement results showed the highest hardness obtained in the course of research was characteristic for the sample with the numbers $4,5,14,17,18$, 
28 , and the hardness range is $840-855 \mathrm{HL}$. These samples correspond to the orientation of a synthesized model on the Eden 350 framework with the maximum overall dimension located along the axes $\mathrm{X}$ and $\mathrm{Y}$. The sample coating surface and support material nature does not significantly influence the hardness.

Flat samples with a cross-sectional area $S_{0}$ of a standard size from a researched photopolymeric material FullCure 720 were fixed in the test machine grips and stretched under the action of a continuously growing load until breaking. To make it possible to compare the sample test results, one needs to make a dependency between the voltages $\sigma$ $(\mathrm{MPa})$ occurring in sample cross sections and a relative sample elongation $\varepsilon(\%)$. To do this, let us recalculate the experimentally obtained data with the help of formulas (1):

$$
\sigma=\mathrm{F} / \mathrm{S}_{0} ; \varepsilon=\left(\Delta \mathrm{l} / \mathrm{1}_{0}\right) \cdot 100 \%,
$$

were $\sigma-$ voltages in cross sections, $(\mathrm{MPa})$;

$\mathrm{F}$ - tensile loading, $(\mathrm{H})$;

$\mathrm{S}_{0}-$ cross section square, $\left(\mathrm{mm}^{2}\right)$

$\varepsilon-$ relative sample elongation, $(\%)$;

$\Delta \mathrm{l}$ - absolute elongation $(\mathrm{mm})$;

$1_{0}$ - initial length (mm).

Numerical values $\sigma$ and $\varepsilon$ fully characterize strength and plastic properties of the sample photopolymeric material at static stretching. The analysis of results (Fig. 1) obtained at the tensile test demonstrated the highest strength and plastic properties of the material FullCure 720 are observed in the samples 3, 6, 7, 9. Such samples are characterized by the maximum dimension location along the $\mathrm{X}$ axis on the unit Objet Eden 350 framework.

A comprehensive analysis of the results obtained in the course of experiments led us to the conclusion that for the layer-by-layer growing process at the unit Objet Eden 350 with the help of the PolyJet technology the key influence on the surface roughness, part geometry reproduction accuracy, prototype strength properties (or a final product in some cases) as well as its hardness is exerted by the model location on the framework with its largest dimension along the $\mathrm{X}$ axis - along the printing block run direction. In case it is impossible to locate the model in such a way, its maximum dimension can be located along the $\mathrm{Y}$ axis which will lead to an insignificant loss in its quality.
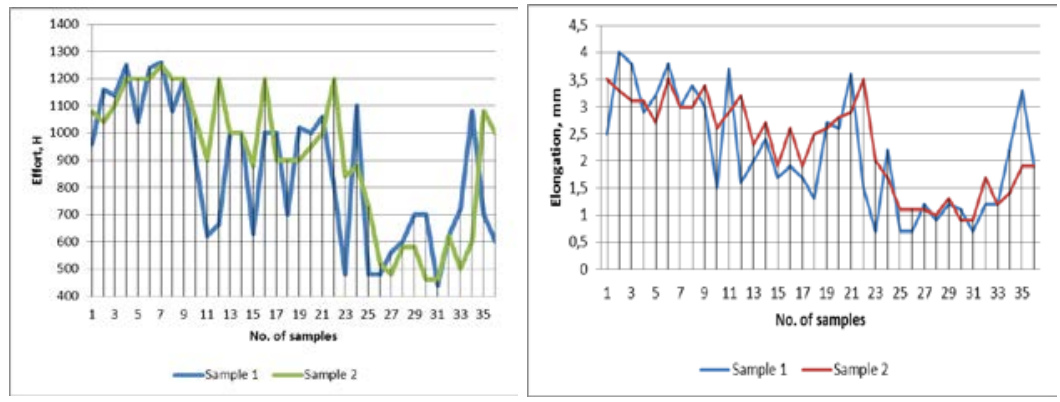

Fig. 1. Results of a tensile test conducted for the samples made of a photopolymeric material.

\subsection{D model preparation to manufacture a solid cast nozzle block}

With the account of technical requirements and conducted research the authors designed a 3D model to make a casting sector of a nozzle block in a CAD module of the programme NX. This stage is a key one to take into account all the product structure details [11].

A special nature of this hot section part is pre-conditioned by the availability of a cooling channel in the airfoil intended for air admission and a gap for the section cooling 
(Fig. 2a). The practice shows that at casting it is difficult to obtain the edge on the pressure side on the gap forming site along the trailing edge (Fig. 26). To provide for the formation of internal cavity and a cooling gap with a ceramic rod, at casting without an allowance for mechanical treatment, one needs to make an allowance on the gap transfer to the airfoil pressure side on the trailing edge with the thickness of $0.3 \div 0.4 \mathrm{~mm}$.

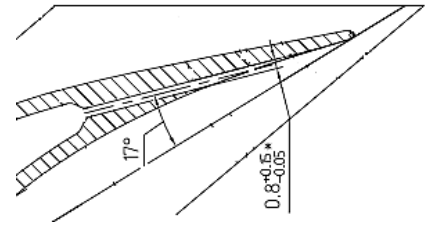

a

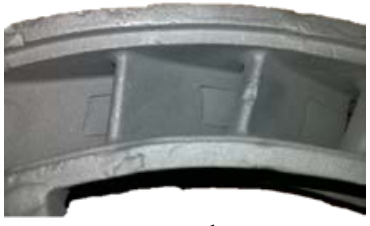

b

Fig. 2. Cooling gap (a) and absence of airfoil edge forming on the pressure side (b).

\subsection{Master mold manufacture for a nozzle block sector}

Taking into account the technical requirements, the 3D printing system Objet Eden 350 helps, by means of a layer-by-layer growing, to grow a master mold of the nozzle block sector from a photopolymeric material (Fig. 3a).

To check the accuracy of obtained geometrical dimensions, the authors conducted the control on the CMM DEA GLOBAL Performance for a grown master mold at the temperature of $20^{\circ} \mathrm{C} \pm 2{ }^{\circ} \mathrm{C}$ and a relative humidity $80 \%$ with the use of a specialized software PC-DMIS CAD ++ Ver. 4.3 MR1[12].

To obtain a required roughness of a grown master mold, the following operations were introduced into the technological process:

1. Master mold roughness control at a profilometer after growing.

2. Polishing of hot section and airfoil surfaces of a nozzle block up to the roughness Ra 1.6.

3. Master mold roughness control at a profilometer after polishing.

4. Control of geometrical parameters of the section surfaces and airfoil nozzle block.

After a final control of the airfoil geometry and locking part of a master mold one starts to manufacture an elastic silicone mold [13].

\subsection{Wax model manufacture}

The difficulty of manufacturing sector wax models consisted in the presence of an internal cavity to obtain which ceramic rods were used. Ceramic rods were preliminary based in the elastic silicone mold. After wax filling with wax in vacuum conditions one obtains an accurate master mold copy. A silicone mold can endure 80-100 castings. The parameters of wax filling into the silicone mold: temperature filling of $95^{\circ} \mathrm{C}$, cooling forced air forging, wax model holding time in the mold 2 hours 30 minutes. A ready wax model of a nozzle block is represented in Fig. 3. 


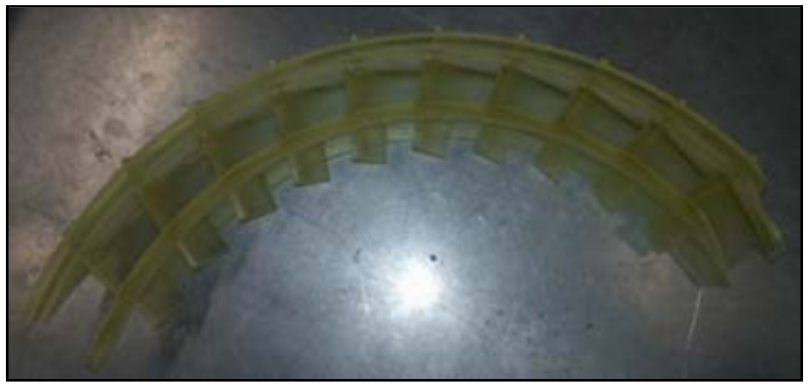

a

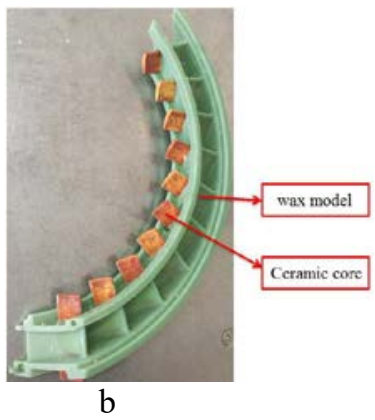

b

Fig. 3. Master mold (a) and wax model of (b) the GTE nozzle block sector.

After getting the sector wax models of 10 blades one conducted the control of geometric parameters of the sector wax models at the CCM DEA GLOBAL. The models which successfully passed the control operation are assembled into a nozzle block wheel, three items per a wheel, (Fig. 4) with the use of a mandrel for an accurate positioning of the wax models of nozzle block blade sectors along the wheel internal diameter. Further, the sectors are soldered, after that a gating supply system formed and a ceramic coating are formed; then, one fills the metal into a ceramic mold according to the casting technology on the invested models [14].

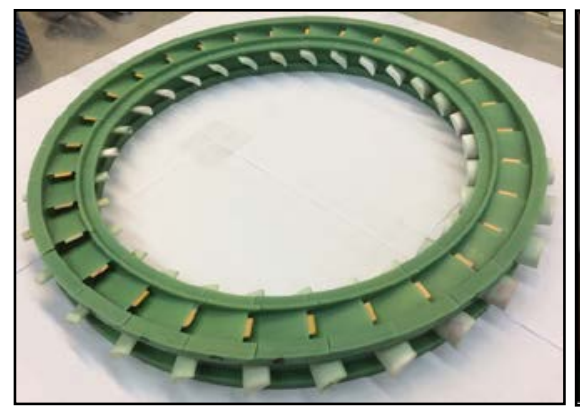

a

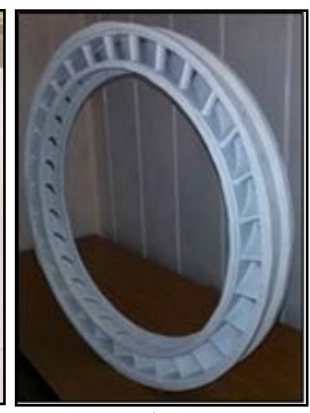

$\mathrm{b}$

Fig. 4. Nozzle block wheel of a GTE hot section: $a$ - wax model; $b$ - casting.

\section{Conclusions}

In the process of work a technological process was developed and optimized. This process is intended for a preliminary production of a solid cast nozzle block with the use of highspeed prototyping which fully corresponds to the set technical requirements and the surface layer quality. Further, the authors conducted a number of research allowing one to obtain optimal parameters for sector master mold growing. The authors developed a technological process to manufacture a solid cast nozzle block providing for the contraction of the manufacturing terms as well as for the reduction of the product net cost. The solid cast nozzle block wax models were obtained. The tooling to assemble separate wax models was developed and manufactured. Finally, a trial wheel filling for a GTE solid cast nozzle block was performed.

These studies were conducted on the equipment of CAM technology common use center (RFMEFI59314X0003).This work was supported by the Ministry of education and science of the Russian Federation in the framework of the implementation of the Program "Research and development on priority directions of scientific-technological complex of Russia for 2014-2020". 


\section{References}

1. R.A. Vdovin, V.G. Smelov, M.A. Bolotov, N.D. Pronichev, IOP Conference Series: Materials Science and Engineering, Vol. 142, Issue 1, 012073 (2016)

2. A. Kampker, K. Kreisköther, C. Reinders International Scholarly and Scientific Research \& Innovation, 11(3), pp.242-249 (2017)

3. A. Cazón, P. Morer, L.Matey Proc IMechE Part B: J Engineering Manufacture, Volume: 228 issue: 12, pp.1664-1675 (2014)

4. C. S. Carolyn, G. Tyler, K. Kim, [et al] 23rd Annual International Solid Freeform Fabrication Symposium, Austin, TX., pp. 921-931 (2012).

5. P. Fastermann, Rapid Prototyping. Düsseldorf, Springer Verlag Berlin Heidelberg, pp. 114-128 (2012)

6. B. Caulfield, P.E. McHugh, S. Lohfeld Journal of Materials Processing Technology 182, pp. 477-488 (2007)

7. A. Pilipović, P. Raos, M. Šercer, Int J Experimental analysis of properties of materials for rapid prototyping, Adv Manuf Technol 40, pp.105 (2009).

8. R. Quintana, J-W. Choi, K. Puebla ASTM D638 type 1 specimens. Int J Adv Manuf Tech 46, pp. 201-215 (2010)

9. L.F. Vieira, R.A. Paggiand, G.V. Salmoria, Innovative Developments in Virtual and Physical Prototyping: Proceeding, pp.385-388 (2012)

10. GOST 1497-84. Metals. Methods of Tension Test (Revisions N. 1, 2, 3) Introduction date 1986-01-01, M.: Standardinform (2008)

11. A.V. Balaykin, K.A. Bezsonov, M.V. Nekhoroshev, A.P. Shulepov, IOP Conference Series: Materials Science and Engineering, 302(1), 012009 (2018)

12. A.V. Balyakin, E. M. Dobryshkina, R. A. Vdovin, V. P. Alekseev IOP Conf. Series: Materials Science and Engineering 327(2), 022025 (2018)

13. A.V. Agapovichev, A.V. Balaykin, V.G. Smelov, Modern Applied Science, 9 (4), pp. 335-343 (2015).

14. I.S. Stepanenko, A.I. Khaimovich, IOP Conference Series: Materials Science and Engineering, 177 (1),012093 (2017) 